\title{
Effects within the week on forced vital capacity are correlated with long term changes in pulmonary function: reanalysis of studies on car painters exposed to isocyanate
}

\author{
Monica Dahlqvist, Göran Tornling, Nils Plato, Ulf Ulfvarson
}

\begin{abstract}
Objectives-To examine if car painters who work with polyurethane paints that contain hexamethylenediisocyanate (HDI) and hexamethylenediisocyanate biuret trimer (HDI-BT) develop acute as well as chronic impairment of lung function.

Methods-In this study data were reanalysed from two earlier studies on a group of car painters to see if a decrease in lung function within the week is a marker of vulnerability in those workers. Data on changes in forced vital capacity (FVC) and forced expiratory volume in one second $\left(F E V_{1}\right)$ within the week were available for 20 car painters who were also examined six years later.

Results-10 men showed a decline in FVC within the week. There were no significant differences in age, duration of employment, exposures during the follow up period, or smoking between car painters who had decline in lung function within the week and car painters who had not. A significant correlation was found between the change in FVC within the week and the long term (six year) change in FVC, standardised for the effects of aging and smoking, and adjusted for the number of peak exposures.

Conclusions-The results suggest that the decrease in FVC within the week might serve as a guide to identify car painters at risk of a further decrement in lung function above the effects of aging, smoking, and exposure.
\end{abstract}

(Occup Environ Med 1995;52:192-195)

Keywords: forced vital capacity; deterioration of pulmonary function; diisocyanates; painters

Measurements of dynamic lung volumes such as forced vital capacity (FVC) and forced expiratory volume in one second $\left(\mathrm{FEV}_{1}\right)$ are powerful measures to examine the effects of certain exposures on lung function. In several studies we have found acute temporary effects on FVC and $F_{E V}$ in workers exposed to irritating air contaminants. ${ }^{1-5}$ These temporary effects were correlated with the concentration of the air contaminants. The measurement of acute effects from irritants on lung function is of value as a complement to exposure measurements. It is also of great interest to study the medical importance of acute temporary effects. The results from a recently published study indicated that a change in $\mathrm{FEV}_{1}$ within the week was correlated with an accelerated decline in lung function in asymptomatic wood trimmers. ${ }^{6}$ An accelerated decline in FVC, correlated with long term exposure, has been found in car painters, ${ }^{7}$ although the mean values for FVC and $F E V_{1}$ in those painters were unaltered during a working week. ${ }^{8}$ The effects of exposure may be difficult to find due to the normal diurnal variation in lung function. ${ }^{6910}$ If the short term decrease during a workshift or week cannot be associated with the exposure, it is possible that subjects who show a decrease are vulnerable. By measuring lung function during a working shift or week, such subjects may be identified and measures can be taken to decrease or stop the exposure.

Polyurethane car paints contain hexamethylenediisocyanate (HDI) and hexamethylenediisocyanate biuret trimer (HDI-BT), which is a polycondensation product of HDI and water. Isocyanates belong to a group of chemicals that contain the highly reactive isocyanate group $(-\mathrm{N}=\mathrm{C}=\mathrm{O})$. The respiratory effects of exposure to isocyanates include chemical bronchitis, allergic asthma, non-specific bronchial hyperreactivity, chronic deterioration in lung function, and hypersensitivity bronchial pneumonitis. ${ }^{11}$ To evaluate if a decrease in lung function within the week is a marker of vulnerability in workers exposed to isocyanates, we reanalysed the data from two earlier published studies. ${ }^{78}$

\section{Material and methods}

STUDY GROUP

Lung physiological investigations were carried out on two occasions (in 1978 and 1984) in male car painters who worked with polyurethane paints. The original group of car painters were randomly chosen from 14 garages in Stockholm, Sweden. ${ }^{78}$ In February and March 1978, the workers were examined on a Monday before work after two days of no exposure, and again on Friday in the same working week. At the follow up in October and November 1984 the workers were examined during the first three hours of a working day. Twenty eight car painters participated in all three spirometric examinations, but only those 20 car painters who had been working during the entire period 1978-84 were chosen. At the time of the follow up their mean age was 41 years. There were four never smokers, six ex-smokers and 10 current 
smokers. There were no significant differences in age, height, smoking habits, and symptom score between this group and the entire group studied in 1978 or 1984 .

\section{EXPOSURE CONDITIONS}

An industrial hygienist, blinded to the medical condition of the workers, performed individual assessments of exposure to HDI and HDIBT during 1978-84. All car painters were interviewed about their working routines and use of respirators. Hygienic standards were studied and exposure measurements were carried out at representative shops. A total of 81 measurements were performed for three different worktasks and in 25 different spray painting chambers, classified according to the number of air changes/hour. To find situations when peak exposure occurred-that is, concentrations $>2.0 \mathrm{mg} / \mathrm{m}^{3}$ HDI-BT for at least 30 seconds-exposure measurements with a sampling time of $<3$ minutes were carried out. Peak exposure to HDI-BT occurred when, without respiratory protection of any kind, the subject was cleaning a spray gun or stayed within the spraying chamber for more than 20 seconds before it was ventilated. ${ }^{7}$ For the car painters studied, the calculated time weighted average exposure between 1978 and 1984 was $0.0014 \mathrm{mg} / \mathrm{m}^{3} \mathrm{HDI}$ and $0.09 \mathrm{mg} / \mathrm{m}^{3}$ HDI-BT, which is lower than measured or estimated values in 1984. Median of yearly number of peak exposures to HDI-BT was 2000 .

\section{SPIROMETRY}

Forced expiratory vital capacity manoeuvres were carried out with a calibrated low resistance bellows spirometer (Ohio 740). The subject was seated and was carefully instructed before the test was performed. Each man carried out three tests. The best result for each variable was chosen, even if the results were selected from different recordings. ${ }^{12}$ In our study FVC and FEV, were measured.

Table 1 Mean (SD) age, duration of employment yearly number of peak exposures, and percentages of ex and current smokers at follow up for 20 car painters with and without a decrease in FVC within the week

\begin{tabular}{lcc}
\hline & $\begin{array}{l}\text { With } \\
(n=10)\end{array}$ & $\begin{array}{l}\text { Without } \\
(n=10)\end{array}$ \\
\hline Age (y) & $41(12)$ & $42(8)$ \\
Duration of employment (y) & $25(13)$ & $22(9)$ \\
Exposure 1978-84 (peaks/y) & $2573(1719)$ & $1785(1410)$ \\
Ever smokers (\%) & 80 & 80 \\
\hline
\end{tabular}

Table 2 Number of subjects with respiratory symptoms at the initial study and six years later, divided into car painters with and without a change in FVC within the painter

\begin{tabular}{llc}
\hline & With $(n=10)$ & Without $(n=10)$ \\
\hline 1978: & & \\
Chronic bronchitis & 1 & 1 \\
Cough & 2 & 1 \\
Dyspnoea & 4 & 3 \\
Wheeze & 3 & 0 \\
1984: & & 0 \\
Chronic bronchitis & 1 & 1 \\
Cough & 3 & 3 \\
Dyspnoea & 3 & 3 \\
Wheeze & 3 & \\
\hline
\end{tabular}

\section{STATISTICAL ANALYSIS}

Standard statistical methods were used, in conjunction with multiple regression analyses. ${ }^{13}$ Change in lung function within the week in each man was calculated according to the formula:

$$
\text { change }=100 \frac{(\text { after }- \text { before })}{0 \cdot 5(\text { after }+ \text { before })}
$$

Lung function values obtained in 1978 were expressed as percentages of the expected values from the European summary equations. ${ }^{14}$ The values obtained at the second occasion in 1984 were standardised for the long term effects of aging and smoking found in a population. ${ }^{15}$ The long term decline in lung function between the first and the second study in each man was calculated according to the formula:

$$
\text { decline }=100 \frac{(2 \mathrm{nd}-1 \mathrm{st})}{0.5(2 \mathrm{nd}+1 \mathrm{st})}
$$

The absolute values obtained at the first and the second study were used in the formula. Appropriate transformations were applied to those variables found to have a distribution that diverged from normality. As the aim of this study was to evaluate if subjects who had a decrease in lung function within the week are vulnerable, the changes in FVC and $\mathrm{FEV}_{1}$ within the week were dichotomised. A change $<0 \%$, signifying a decrease, was scored $1-$ that is, an effect was indicated. A change $\geqslant$ $0 \%$ (no decrease) was scored 0 -that is, no effect was indicated. Stated $P$ values involved two tailed analysis; differences were considered to be significant at $P \leqslant 0.05$.

\section{Results}

The mean (SEM) changes in FVC and FEV during a shift in 1978, were $-0.6(2.6)$ and $-3.6(4 \cdot 1) \%$ respectively. Age, duration of employment, yearly number of peak exposures to HDI-BT, and distribution of smoking habits did not differ significantly between the 10 car painters who showed a decrease in FVC and those who did not (table 1). There were no significant differences between the two groups in the distributions of acute or chronic respiratory symptoms in 1978 or in 1984 (table 2). A similar lack of difference was found for the 10 car painters who had and 10 who had no change in $\mathrm{FEV}_{1}$ within the week. The changes in FVC and FEV 1 within the week were also well correlated $\left(r^{2}=56 \%\right.$, $P=0.009$ ). The mean values of the changes for FVC and FEV 1 within the week for never smokers were $4.0(6.9)$ and $5 \cdot 8(9.2) \%$ respectively, compared with the corresponding values of $-0.5(3.5)$ and $-5.7(5.2) \%$ for the 10 car painters who were current smokers in both studies $(P>0.2)$. The decline in FVC was significantly greater in current smokers $(-5.9(2.7))$ than in never smokers $(4.4$ $(3 \cdot 3))$. Current smokers had on average a higher yearly number of peak exposures to HDI-BT than did never smokers (2928 (454) $v 762$ (367), $\mathrm{P}<0.05$ ).

Car painters in the initial study who showed a decrease of FVC within the week in 
Table 3 Mean (SEM) percentage of predicted lung function ${ }^{14}$ at the initial investigation and changes from 1978 to 1984 for car painters with and without decrease in FVC and $F E V_{1}$ within the week

\begin{tabular}{|c|c|c|c|c|}
\hline & \multicolumn{2}{|l|}{$F V C$} & \multicolumn{2}{|l|}{$F E V_{l}$} \\
\hline & With $(n=10)$ & Without $(n=10)$ & With $(n=10)$ & Without $(n=10)$ \\
\hline \multicolumn{5}{|l|}{ FVC: } \\
\hline $\begin{array}{l}\text { Initial 1978 } \\
\text { Decline 1978-84† } \\
\text { FEV }_{1} \text { : }\end{array}$ & $\begin{array}{l}112 \cdot 1(3 \cdot 7) \\
-8 \cdot 1(2 \cdot 6) \ddagger\end{array}$ & $\begin{array}{r}104.6(5 \cdot 0) \\
0.5(2 \cdot 6)\end{array}$ & $\begin{array}{l}113 \cdot 0(2 \cdot 9) \\
-7 \cdot 4(2 \cdot 5)\end{array}$ & $\begin{array}{l}103 \cdot 7(5 \cdot 4) \\
-0 \cdot 2(2 \cdot 9)\end{array}$ \\
\hline $\begin{array}{l}\text { Initial } 1978^{\star} \\
\text { Decline } 1978-84 \dagger\end{array}$ & $\begin{array}{r}98 \cdot 3(4 \cdot 9) \\
4 \cdot 4(6 \cdot 1)\end{array}$ & $\begin{array}{r}99.3(6.5) \\
1.9(5.0)\end{array}$ & $\begin{array}{r}100 \cdot 8(4 \cdot 2) \\
2 \cdot 3(6 \cdot 4)\end{array}$ & $\begin{array}{r}96.9(6.9) \\
4.0(4.6)\end{array}$ \\
\hline
\end{tabular}

*Lung function at first occasion, standardised for age and height; tpercentage of the change in lung function standardised for the effects of aging and smoking; $¥$ significantly lower compared with car painters without a decrease in FVC within the week.

1978 had a significantly greater decline in FVC from 1978 to 1984 , than car painters who did not, after adjustment for smoking (table 3). There was a significant correlation between the change in FVC within the week in the first study and the decline in FVC during the six year follow up $\left(r^{2}=47 \%, \mathrm{P}=\right.$ $0.005)$. The six year decline in FVC was still correlated with the yearly number of peak exposures to HDI-BT, after adjustment for the effects of changes in FVC within the week $\left(r^{2}=32 \%, \mathrm{P}=0.009\right)$ and also to the change in FVC within the week adjusted for the effects of yearly number of peak exposures to HDI-BT ( $r^{2}=32 \%, P=0.009$, figure).

Car painters who showed a change in FEV within the week in 1978 had a tendency to a greater six year decline in FVC $(P=0.08$, table 3 ). There were no significant correlations either between the change in FVC during a shift and the long term decline in $\mathrm{FEV}_{1}$ or the change in $\mathrm{FEV}_{1}$ within the week and the long term decline in FVC and $F_{E V}$. The decline in FVC was not significantly correlated with the mean exposure to HDI or HDIBT estimated during the entire follow up.

\section{Discussion}

A significant correlation was found between the changes within the week and the six year decline in FVC standardised for age and smoking, adjusted for the effects of yearly number of peak exposures to HDI-BT in car painters (figure). The distributions of respiratory symptoms were similar in those car painters who showed a decrease in FVC during a working week and those who did not (table

Correlation in car painters between the changes in FVC (\%) within the week and the long term changes in FVC (\%) standardised for the effects of aging and for the effects of aging and
smoking's at the follow up six years after initial study adjusted for the effects of yearly number of peak exposures to HDI-BT

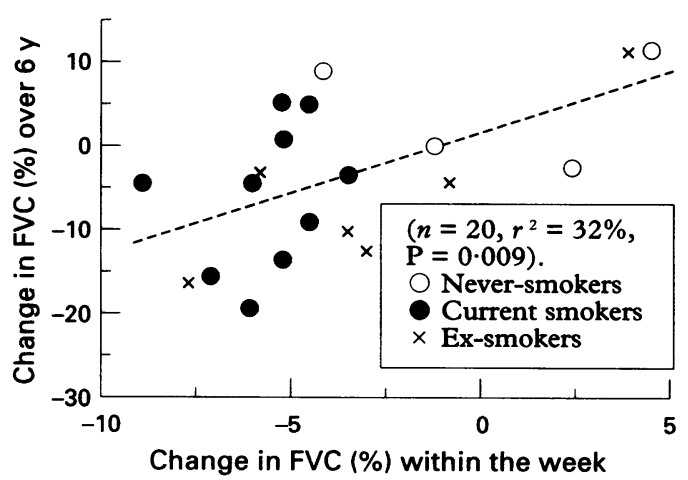

2). Thus the correlation between the changes within the week and a long term decline in FVC is not likely to be influenced by the presence of symptoms, which have been shown to predict a decrease in lung function. ${ }^{16}$ Changes in $\mathrm{FEV}_{1}$ within the week have been shown to predict pulmonary impairment in wood trimmers without any respiratory illness and without any acute or chronic symptoms. ${ }^{6}$

In the first study, there was a slight average decrease in FVC and in $\mathrm{FEV}_{1}$ within the week in this group of car painters. The car painters were examined before (in the morning) and after a working week (in the afternoon). The normal circadian rhythm in FVC and FEV will result in higher values in the afternoon compared with morning values ${ }^{910}$ and the difference seems to be larger for $\mathrm{FEV}_{1}$ than for FVC. ${ }^{17}$ Therefore, a numerically small nonsignificant decrease in FVC or $\mathrm{FEV}_{1}$ during a working week may be of importance in the long run, as the effects of exposure may be overridden due to the normal variation in lung function. Although there were trends towards greater changes in FVC and $\mathrm{FEV}_{1}$ within the week in current smokers, the differences when compared with the results obtained for never smokers were not significant. The distribution of smoking habits was also identical between car painters who had a decrease in FVC and those who had not. It is therefore not likely that active smoking should have resulted in a decrease in FVC within the week. This is in agreement with previously reported results. ${ }^{10}$

There was no significant correlation between the decline in FVC from 1978 to 1984 and the estimated mean exposures to HDI or HDI-BT during the entire follow up time. On the other hand there was a correlation between the decline in FVC and yearly number of peak exposures to HDI-BT also after adjustment for the effects of the change in FVC within the week. The number of peak exposures was related to each car painter's working routine and the use of protective equipment during short working operations.? It is noteworthy that the current smokers on average had a significantly higher yearly number of peak exposures and also a greater decline in FVC than did the never smokers. This may indicate that car painters who smoke are less likely to use respiratory protection in highly exposed situations and therefore show a greater decline in lung function. The unadjusted decline in FVC for men who were ex-smokers and current smokers at both occasions were 72 , and $91 \mathrm{ml} /$ year, respectively. This is about twofold higher than the decline found in a population study standardised for the effects of aging and smoking. ${ }^{15}$ Although it may be questionable to standardise long term effects on lung function without quantification of smoking, the findings in our study may indicate additional harmful effects of yearly number of peak exposures to HDI-BT in smokers.

The main finding in this study is a correlation between the changes in FVC within the week and long term changes in FVC, after adjustment for the effects of yearly number of 
peak exposures to HDI-BT. If the long term exposure was representative of the exposure over the week, the observed correlation between short term and long term deterioration in lung function could be explained by differences in exposure. This could be the case in a population with specialised work or workers from different workplaces with very different exposure conditions. It cannot be entirely excluded that the average long term exposure is representative of the exposure during one week. We think, however, that the exposures vary too much in the long term for us to obtain the results observed. Another explanation could be that smoking is a confounder related to both short and long term impairment of lung function and also to HDI exposure due to less use of protective equipment by smokers. We find it probable, however, that those workers who show an acute decrease in lung function over a week are more vulnerable than other workers, and that repeated exposures in these workers will result in a long term chronic decrease in their lung function.

1 Dahlqvist M, Johard U, Alexandersson R, Bergström B, Ekholm U, Milosevich B, et al. Lung function and precipitating antibodies in low exposed wood trimmers in Sweden. Am f Ind Med 1992;21:549-59.

2 Ulfvarson U, Alexandersson R. Reduction in adverse effect on pulmonary function after exposure to filtered diesel exhaust gases. Am $\mathcal{f}$ Ind Med 1990;17:341-7.
3 Ulfvarson U, Alexandersson R, Dahlqvist M, Ekholm U, Bergstrom B. Pulmonary function in workers exposed to diesel exhausts: the

4 Ulfvarson U, Alexandersson R, Dahlqvist M, Ekholm U, Bergström B, Scullman J. Temporary health effects from exposure to water-borne paints. Scand $\mathcal{f}$ Work Environ Health 1992;18:376-87.

5 Dahlqvist $M$, Ulfvarson $U$, Bergström B, Ekholm $U$ Temporary effects on lung function in welders engaged in cored wire welding. Occup Hyg 1994;1:119-26.

6 Dahlqvist M, Ulfvarson U. Acute effects on forced expiratory volume in one second and longitudinal change in pulmonary function among wood trimmers. Am $y$ Ind Med 1994;25:551-8.

7 Tornling G, Alexandersson R, Hedenstierna G, Plato N. Decreased lung function and exposure to diisocyanates (HDI and HDI-BT) in car repair painters: observations (HDI and HDI-BT) in car repair painters: observations on re-examination 6 year

8 Alexandersson R, Plato N, Kolmodin-Hedman B Hedenstierna G. Exposure, lung function, and symptoms in car painters exposed to hexamethylenediisocyanate and biuret modified hexamethylenediisocyanate. Arch Environ Health 1987;42:367-73.

9 Dimich HD, Sterling TD. Ventilatory function changes over a workshift. Br ₹ Ind Med 1981;38:152-5.

10 Love RG. Lung function studies before and after a work shift. Br F Ind Med 1983;40:153-9.

11 Musk AW, Peters JM, Wegman DH. Isocyanates and respiratory disease: current status. Am F Ind Med 1988; piratory disea

12 Gardner RM. ATS statement-Snowbird workshop on standardization of spirometry. Am Rev Respir Dis standardization

13 Ferguson GA. Statistical analysis in psychology and education, 5th ed. New York: McGraw-Hill, 1981.

14 Quanjer PhH, Dalhuijsen A, van Zomeren BC. Summary equations of reference values. Bulletins of Physiopathology of Respiration 1983;19(suppl 5):45-51.

15 Huiti E, Ikkala J. A 10-year follow-up study of respiratory symptoms and ventilatory function in a middle-aged rural population. Eur $₹$ Respir Dis 1980;61:33-45.

16 Olofsson J, Skoogh B-E, Bake B, Svärdsudd K. Mortality related to smoking habits, respiratory symptoms and lung function. Eur $f$ Respir Dis 1987;71:69-76.

17 Hruby J, Butler J. Variability of routine pulmonary function tests. Thorax 1975;30:548-53. 